\title{
Efficiency evaluation in an airline company: some empirical results
}

\author{
Mauro Coli \\ Dipartimento di Metodi Quantitativi e Teoria Economica \\ Università “G.D’Annunzio” Chieti-Pescara \\ coli@unich.it \\ Eugenia Nissi \\ Dipartimento di Metodi Quantitativi e Teoria Economica \\ Università “G.D’Annunzio” Chieti-Pescara \\ nissi@dmqte.unich.it \\ Agnese Rapposelli \\ Dipartimento di Metodi Quantitativi e Teoria Economica \\ Università “G.D’Annunzio” Chieti-Pescara \\ agnese.rapposelli@virgilio.it
}

\begin{abstract}
During the last years enormous attention has been given to the assessment and improvement of the performance of productive systems. In this context, there are two types of modelling methods of efficiency measurement: a non parametric one, represented by Data Envelopment Analysis (DEA), and a parametric one, represented by Stochastic Frontier Analysis (SFA). The main objective of this empirical study is to evaluate the operational performance of an Italian airline for the year 2007 by using these two alternative methodologies. Then, the technical efficiency estimates obtained from the two techniques are compared.
\end{abstract}

Keywords: airline industry, productive efficiency, Data Envelopment Analysis (DEA), Stochastic Frontier Analysis (SFA).

\section{Introduction}

Over the past two decades, the growing of the air transport demand, the technological progress, the strong investments in the field and the aviation deregulation have determined a rapid development of air transportation.

Recently, considerable attention has been focused on the performance of various airlines and air carriers in terms of efficiency and the operational performance of air carriers has received significant attention in the literature. In fact, the deregulation process has been primarily argued for on the basis of improving competition and hence efficiency in the provision of air transport services.

There are many ways in which one may define and measure efficiency of industrial activities such as air transportation. Modern efficiency measurement begins with Farrell (1957), who suggested to measure efficiency in terms of distance to the best unit on the frontier. Drawing inspiration from his argument, two classes of methods, Data Envelopment Analysis (DEA) and Stochastic Frontier Analysis (SFA), were developed for estimating the efficiency of Decision Making Units (DMUs) which use the same set of inputs to produce the same sets of outputs. DEA technique assumes that all deviations from the efficient frontier is due to inefficiency, while SFA technique assumes that deviations from the efficient frontier can be either a realisation of inefficiency or a random shock. The two approaches are traditionally thought to be competing, but there is no consensus as to which is the most appropriate technique, each has its own strengths and weaknesses (Coli, Nissi, Rapposelli, 2007). Consequently, in our opinion the two methods should be used in conjunction. 
Hence, the aim of this paper is to analyse the efficiency of an Italian airline, Air One S.p.A., for the year 2007 by estimating a parametric function using econometric methods (SFA) and a nonparametric function using mathematical programming approach (DEA), and to make a comparison between the results of the methods.

The paper is organised as follows. Section 2 describes the two modelling methodologies, Section 3 presents the data used in the analysis, Section 4 discusses the empirical findings and Section 5 concludes.

\section{Methods}

\subsection{Stochastic Frontier Analysis (SFA)}

In the parametric approach of efficiency measurement the production technology is modelled with a single output production function:

$y_{i}=f\left(x_{i} ; \beta\right)-u_{i}, \quad i=1, \ldots, n$

where $y_{i}$ denotes the output of DMU i, $x_{i}$ denotes the vector of its inputs levels, $\beta$ is a vector of parameters to be estimated and $u_{i}$ is a non-negative random variable which capture the technical inefficiency of DMU i.

In this context Stochastic Frontier Analysis measures the technical efficiency relative to a stochastic parametric frontier (Aigner, Lovell and Scmidt, 1977; Meeusen and van den Broeck, 1977) and assumes $\varepsilon_{i}$ is a composed error term. The stochastic frontier production function for cross-sectional data, in this case, is defined as a Cobb-Douglas:

$\ln y_{i}=f\left(x_{i} ; \beta\right)+v_{i}-u_{i}, \quad i=1, \ldots, n$

where $v_{i}$ represents the symmetric normal term capturing randomness outside the control of the DMU (for example measurement error, effects of weather, luck, etc.) and $u_{i}$ is a one-sided component measuring unit-specific inefficiency. The $v_{i}$ s are assumed to be independently and identically distributed as $N\left(0, \sigma_{V}^{2}\right)$, the $u_{i}$ s are non-negative and are assumed to be distributed independently of $v_{i}$. The inefficiency, in this case, is assumed to be distributed half-normally.

The technical efficiency of DMU i is given by:

$T E_{i}=\exp \left(-u_{i}\right)$,

where the best predictor for $u_{i}$ is the conditional expectation of $u_{i}$, given the value of $v_{i}-u_{i}$.

\subsection{Data Envelopment Analysis (DEA)}

An alternative method for assessing the productive efficiency is Data Envelopment Analysis. Rather than explicitly stating the form of the frontier, it measures efficiency relative to a deterministic frontier using linear programming techniques to envelop observed input - output vectors as tightly as possible.

The basic DEA model, developed by Charnes, Cooper and Rhodes (1978), is built on the assumption of constant return to scale of activities (CRS). Assuming input reduction (which objective is to minimize inputs while producing at least the given output levels), the model is as follows:

$e_{0}=\min \theta_{0}$

subject to

$\theta_{0} x_{i j 0}-\sum_{j=1}^{n} \lambda_{j} x_{i j} \geq 0, \quad i=1, \ldots, m$

$\sum_{j=1}^{n} \lambda_{j} y_{r j} \geq y_{r j 0}, \quad r=1, \ldots, s$ 
where $y_{r j}$ is the amount of the r-th output to DMU j, $x_{i j}$ is the amount of the $\mathrm{i}$-th input to DMU $\mathrm{j}$ and $\lambda_{j}$ are the weights of DMU j.

The variable returns to scale (VRS) model is obtained by adding the convexity constraint: $\sum_{i=1}^{n} \lambda j=1$

\section{Data}

We apply these two different methodologies to analyse the efficiency of Air One routes for the year 2007. Our sample consists of 43 domestic routes: to respect the homogeneity assumption, we do not consider international routes, summer routes and any routes which have not been operating all the year.

A lot of studies have used parametric or non-parametric methods to investigate the performance of the airline industry, but there is no definitive study to guide the selection of inputs and outputs in airlines applications of efficiency measurement. We define a model characterised by two inputs, total seats and variable direct operating costs (DOCs), and one output, scheduled revenue: it should be clear that each of the inputs and outputs in the model reflects the operational characteristics of the airline company.

The number of seat available for sale provides information about airline capacity. DOCs depend upon the airline's activity level and they are directly escapable in the short run, hence they could be avoided if a flight or a series of flights was cancelled. This variable includes numerous items such as fuel costs, handling, variable flight crew costs (for example bonuses), landing and airport fees, passenger meals, variable maintenance expenses, check costs. We have not considered asset-related inputs, i.e. those inputs that represent capital goods because they contribute to costs only indirectly through depreciation, amortisation and interests.

The output considered in our model is passenger scheduled revenue, which is the main output for a typical passenger focused airline. We have not included charter revenue and all output that is not passenger-flight related, such as cargo revenue.

Moreover, we have decided to consider a special kind of outputs, an undesirable output represented by the number of delayed flights, which represents a negative factor in terms of costs and in terms of imagine towards customers. All data were obtained from various internal reports.

\section{Results}

We obtain maximum-likelihood estimates of the parameters of the stochastic frontier model (1) with the output and inputs variables defined in Section 3 using the program Stata 9. The nonparametric efficiency measures are computed under the assumption of constant returns to scale (CRS) which, according to Good et al. (1995), is consistent with the vast majority of the airline literature, and with an input-oriented formulation. We use the program developed by Kaoru Tone, DEA-Solver, to solve this linear model.

Table 4.1 shows the efficiency ratings for each routes assessed, calculated according to the models presented in Section 2. The two sets of results provide similar rankings of the routes in terms of efficiency, although the SFA efficiency ratings are not in the same order as those obtained from the DEA. Some different remarks can be made: although the parametric approach yields a higher average efficiency score and displays less variability than the non-parametric approach, in terms of SFA only one route is fully efficient while in terms of DEA model three routes are fully efficient.

On the basis of these results we proceed to a correlation analysis among the efficiency measures obtained from the stochastic frontier and DEA models. We observe a high Spearman rank correlation coefficient $(0,6739)$ between the technical efficiency scores obtained from the two models. 


\begin{tabular}{l|l|l|l|l|l|l|l|l}
\hline DMU & $\begin{array}{l}\text { SFA } \\
\text { score }\end{array}$ & $\begin{array}{l}\text { DEA } \\
\text { score }\end{array}$ & DMU & $\begin{array}{l}\text { SFA } \\
\text { score }\end{array}$ & $\begin{array}{l}\text { DEA } \\
\text { score }\end{array}$ & DMU & $\begin{array}{l}\text { SFA } \\
\text { score }\end{array}$ & $\begin{array}{l}\text { DEA } \\
\text { score }\end{array}$ \\
\hline 1 & 0,5802 & 0,4813 & 16 & 0,8616 & 0,5752 & 31 & 0,8567 & 0,9661 \\
\hline 2 & 0,3723 & 0,2624 & 17 & 0,8864 & 0,8457 & 32 & 0,8908 & 0,9322 \\
\hline 3 & 0,8361 & 0,5751 & 18 & 0,7513 & 0,5290 & 33 & 0,8015 & 0,6102 \\
\hline 4 & 0,9130 & 0,8796 & 19 & 0,4788 & 0,2574 & 34 & 0,9230 & 1,0000 \\
\hline 5 & 0,9040 & 0,8486 & 20 & 0,8079 & 0,6306 & 35 & 0,7738 & 0,7407 \\
\hline 6 & 0,9081 & 0,7656 & 21 & 0,5982 & 0,4200 & 36 & 0,7323 & 0,6412 \\
\hline 7 & 0,7975 & 0,5972 & 22 & 0,6590 & 0,4956 & 37 & 0,7385 & 0,5843 \\
\hline 8 & 0,4689 & 0,4190 & 23 & 0,8395 & 0,5419 & 38 & 0,6630 & 0,5660 \\
\hline 9 & 0,7947 & 0,5969 & 24 & 0,9032 & 0,9714 & 39 & 1,0000 & 1,0000 \\
\hline 10 & 0,7781 & 0,5388 & 25 & 0,6233 & 0,2981 & 40 & 0,8398 & 0,6993 \\
\hline 11 & 0,7725 & 0,5670 & 26 & 0,6859 & 0,5997 & 41 & 0,9426 & 0,7899 \\
\hline 13 & 0,7386 & 0,5349 & 27 & 0,9144 & 1,0000 & 42 & 0,6451 & 0,6650 \\
\hline 14 & 0,8296 & 0,5683 & 28 & 0,6844 & 0,8019 & 43 & 0,6758 & 0,7367 \\
\hline 15 & 0,5951 & 0,4150 & 29 & 0,7796 & 0,7235 & & & \\
\hline
\end{tabular}

Table 1: SFA and DEA efficiency scores by domestic routes for the year 2007

We can conclude that the two approaches to efficiency measurement, SFA and DEA, are estimating the same underlying efficiency values but the natures of the two methods are very different. This can lead to different estimates for some, or all, of the units under analysis. Neither SFA nor DEA universally gives better results than the other method for all data sets. In our opinion, if both methods are applied to the same data set, a comparison between the results of the methods can be used to obtain a view as to which of the methods is more likely to be giving the better estimates.

\section{Bibliography}

Aigner D.J., Lovell C.A.K., Schmidt P. (1977), Formulation and estimation of stochastic frontier production function models, Journal of Econometrics, 6: 21-37.

Charnes A., Cooper W.W., Rhodes E. (1978), Measuring the efficiency of decision making units, European Journal of Operational Research, 2: 429-444.

Coli M., Nissi E., Rapposelli A. (2007), Efficiency evaluation by means of Data Envelopment Analysis: strengths and weaknesses, in: Metodi, modelli e tecnologie dell'informazione a supporto delle decisioni. Parte prima: metodologie, D’Ambra L., Rostirolla P., Squillante M. (Eds.), FrancoAngeli.

Farrell M.J. (1957), The measurement of productive efficiency, Journal of the Royal Statistical Society, 120: 253-281.

Good D., Nadiri I., Roeller L.-H., Sickles R.C. (1995), Airline efficiency differences between Europe and the US: implications for the pace of EC integration and domestic regulation, European Journal of Operational Research, 80: 508-518.

Meeusen W., van den Broeck J. (1977), Efficiency estimation from Cobb-Douglas production functions with composed errore, International Economic Review, 18: 435-444.

Nissi E., Rapposelli A. (2008), A Data Envelopment Analysis study of airline efficiency, in: Research methodology on Data Envelopment Analysis, Mantri J.K. (Eds.), Brown Walker Press, Florida, in press.

Pels E., Nijkamp P., Rietveld P. (2001), Relative efficiency of European airports, Transport Policy, 8: 183-192.

Sharma K.R., Leung P., Zaleski H.M. (1997), Productive efficiency of the swine industry in Hawaii: Stochastic Frontier vs. Data Envelopment Analysis, Journal of Productivity Analysis, 8: 447-459. 